\begin{tabular}{|c|c|} 
UÁQUIRI & $P$ QPG \\
\hline Hevista do Programa de Pós-Graduação em Geografia \\
UÁQUIRI - PPGGEO, v. 2, n. 2, p. 27-42, ano 2020
\end{tabular}

\title{
AS CORRENTES FILOSÓFICAS NA GEOGRAFIA DA SAÚDE
}

\author{
Pollyana Furtado Machado Anute ${ }^{1 *}$, Iago Sales de Paula ${ }^{1},{ }^{\text {Dr. }}$.Cleilton Sampaio de Farias ${ }^{2,3}$ \\ ORCID: https://orcid.org/0000-0002-2715-4515; https://orcid.org/0000-0002-6380-0289; \\ https://orcid.org/0000-0003-1783-3175.
}

\begin{abstract}
${ }^{1}$ Discentes da Universidade Federal do Acre, Programa de Pós- graduação em Geografia, Rio Branco, Acre, Brasil., 2Professor da Universidade Federal do Acre, Programa de Pós graduação em Geografia, Rio Branco, Acre, Brasil; ${ }^{3}$ Professor do Instituto Federal do Acre, Rio Branco Brasil.

*pollyana.anute@ifac.edu.br
\end{abstract}

Recebido em: 15/09/2020 Aceito em: 26/11/2020 Publicado em: 20/12/2020

DOI: https://doi.org/10.47418/uaquiri.vol2.n2.2020.4348

\begin{abstract}
RESUMO
A Geografia da Saúde é uma antiga perspectiva e uma nova especialização que se utiliza dos conhecimentos geográficos para a compreensão e resolução dos problemas de saúde. Atualmente, essa parte da ciência geográfica tem ganhado importância, sobretudo, pela possibilidade de contribuição no enfrentamento de epidemias e na organização dos sistemas de saúde. Entretanto, quais as correntes filosóficas dão bases para essa nova especialização? Nesse sentido, objetivamos compreender quais as correntes filosóficas têm contribuído na construção do conhecimento da área. Para tanto, realizou-se uma pesquisa descritiva, com abordagem quantitativa, cujos procedimentos técnicos adotados foram do tipo documental, na qual a fonte dos dados foi um importante periódico da área. A análise se deu em cima de todos os artigos publicados pelo respectivo periódico no ano de 2019. Observou-se que, a corrente filosófica predominante foi a positivista, com $66 \%$ dos artigos publicados, nos quais as principais características é o tipo de pesquisa descritiva e a abordagem quantitativa, objetivando, por vezes, auxiliar o direcionamento das políticas de saúde pública, fato concernente com a Vertente da Geografia da Atenção Médica que estava presente em 20 dos 29 artigos analisados e a Abordagem Ecológica.
\end{abstract}

Palavras-chave: Correntes filosóficas; Geografia da saúde; Vertentes; Abordagens.

\section{PHILOSOPHICAL CHAINS IN HEALTH GEOGRAPHY}

\begin{abstract}
Health Geography is an ancient perspective, and a new specialization that uses geographic knowledge to comprehend and resolve health problems. Currently, this part of geographic science has gained importance due to the possibility of coping against epidemics, and in the organization of the health systems. However, what philosophical trains of thoughts provide the base for this new specialization? Thus, our objective is to understand which philosophical trains of thoughts have contributed to the construction of knowledge in this area. Therefore, a descriptive research was carried out, with a quantitative approach, and the technical procedures adopted were documentary type, in which the source of the data went to an important periodical of the area. The analysis was based on all the articles published by the respective journal in 2019. It was observed that the predominant philosophical train of
\end{abstract}


thoughts were the positivistic one, with $66 \%$ of the published articles, in which the main characteristics are descriptive research and the quantitative approach, aiming, to help guide the public health policies, a fact concerning the aspects of Health Geography which was present in 20 of the 29 analyzed articles and an Ecological Approach.

Keywords: Philosophical trains of thoughts; Health Geography; Aspects; Approaches.

\section{CADENAS FILOSÓFICAS EN GEOGRAFÍA DE LA SALUD}

\section{RESUMEN}

La geografía de la salud es una perspectiva antigua y una nueva especialización que utiliza el conocimiento geográfico para comprender y resolver problemas de salud. Actualmente, esta parte de la ciencia geográfica ha ganado importancia, sobre todo, por la posibilidad de contribuir a la lucha contra las epidemias y a la organización de los sistemas de salud. Sin embargo, ¿qué corrientes filosóficas sientan las bases de esta nueva especialización? En este sentido, pretendemos comprender qué tendencias filosóficas han contribuido a la construcción del conocimiento en el área. Para ello, se llevó a cabo una investigación descriptiva, con enfoque cuantitativo, cuyos procedimientos técnicos adoptados fueron de tipo documental, en el que la fuente de los datos fue a un importante periódico del área. El análisis se basó en todos los artículos publicados por la respectiva revista en 2019. Se observó que la corriente filosófica predominante fue la positivista con el $66 \%$ de los artículos publicados en los que las características principales son el tipo de investigación descriptiva y la enfoque cuantitativo, con el objetivo, en ocasiones, de orientar las políticas de salud pública, hecho que en la Línea de Geografía de la Atención Médica estuvo presente en 20 de los 29 artículos analizados y el Enfoque Ecológico.

Palabras clave: Corrientes filosóficas; Geografía de la salud; Hebras; Enfoques.

\section{INTRODUÇÃO}

A Geografia da Saúde (GS) vem sendo desenvolvida como área de conhecimento desde o século XIX, embora existam registros de escritos sobre a relação entre o homem, o ambiente e a saúde desde a antiguidade, a exemplo das obras de Hipócrates (Dos Ares, das Águas e dos Lugares, 480 a.C.) e dos escritos sobre a medicina nas civilizações egípcias de Heródoto, datadas de 500 a.c. (LACAZ, 1972). Pode ser conceituada como "[...] uma antiga perspectiva e uma nova especialização que se ocupa da aplicação do conhecimento geográfico, dos métodos e técnicas na investigação em saúde, na perspectiva da prevenção de doenças" (IÑIGUEZ ROJAS, 2004).

Existem duas principais vertentes da Geografia da Saúde: a Nosogeografia (tradicional), que se propõe à identificação e análise de padrões de distribuição espacial de doenças, e a Geografia da Atenção Médica (mais recente), dedicada à distribuição e planejamento dos componentes infraestruturais e dos recursos humanos do Sistema de Atenção Médica. (PEITER, 2005).

É indubitável que para se ter maior amplitude de entendimento de uma área do conhecimento se faz necessário o estudo epistemológico acerca do estudo em questão. No caso 
da GS, é imprescindível uma investigação acerca das teorias e métodos norteadores para o entendimento da disciplina em questão, de modo que, através do conhecimento das linhas de raciocínios adotadas, exista um aprofundamento mais abrangente da matéria.

De forma geral, na ciência geográfica há a existência de três grandes correntes filosóficas: o Positivismo Lógico, o Materialismo Histórico e Dialético e a Abordagem Fenomenológica, dentro das quais se desenvolvem outras abordagens.

O Positivismo Lógico é caracterizado pelo empirismo, por sua linguagem matemática e pela observação. Em tal visão metodológica o objeto se separa do sujeito, considerando-se como real aquilo que pode ser descrito por meio de hipóteses e deduções, sendo o objeto priorizado em detrimento do sujeito que o pesquisa, uma vez que nessa corrente há a busca e crença na neutralidade científica. (BORGES, 2013).

Já o Materialismo Histórico e Dialético realiza suas análises a partir do entendimento do homem como ser social e histórico. Portanto, há nessa corrente a descrença de neutralidade científica, uma vez que o pesquisador faz parte do contexto histórico-social no qual está inserido. Tal análise é realizada a partir das desigualdades, de modo que as pesquisas direcionadas por esta corrente vão além da aparência e da forma. Por mais que possa haver a utilização de dados, equações, tabelas e gráficos, sua abordagem empírica não se prende ao quantitativo, priorizando-se a análise de discursos e dados contraditórios. (SANTOS, 2015).

\footnotetext{
Possibilita desvendar as relações de produção e sociais concretas, de superar o existente, contidos nas contradições geradas pelo embate capital $\mathrm{x}$ trabalho, promovendo condições para a emancipação do trabalhador, seja em sua relação com o pensamento, seja em relação a ordem social e econômica imposta. (MONKEN, 2016).
}

A Fenomenologia surge como um movimento filosófico ao final do século XIX, na busca de superar a dicotômica existente entre o racionalismo e o empirismo. Sob a afirmação de que toda consciência é intencional. Para essa corrente filosófica, toda consciência tende para o mundo, ou seja, todas elas formam consciência de algum fenômeno ou objeto que nos chama a atenção. (TRIVIÑOS, 1987).

Essa é a forma de fazer Geografia que não prioriza gerar um conhecimento objetivo e/ou teórico, mas um conhecimento que advém das percepções, representações, atividades e valores dos homens em geral. Em outras palavras, é uma Geografia que visa alcançar uma compreensão do mundo, através do estudo das relações das pessoas, do seu comportamento geográfico, de seus sentimentos e de suas ideias em relação aos espaços e aos lugares. A Abordagem Fenomenológica é a que busca ir além da dicotomia sujeito-objeto, caracterizada pelo 
antropocentrismo e por metodologia subjetiva, havendo aceitação do ecletismo metodológico e sendo muito utilizada nas pesquisas qualitativas. (SANTOS, 2015).

Diante de tudo, interroga-se quais correntes geográficas têm orientado as pesquisas na Geografia da Saúde no ano de 2019. Optamos por tal recorte temporal para termos uma constatação precisa dos levantamentos mais atuais realizados pela Geografia da Saúde. Nesse sentido, objetivamos compreender quais as correntes filosóficas têm contribuído na construção do conhecimento da GS.

\section{MATERIAL E MÉTODOS}

Partindo destas premissas, a priori foi feita uma pesquisa bibliográfica (LAKATOS, 2010) para fundamentação de arcabouço teórico acerca das correntes filosóficas norteadoras das pesquisas em Geografia. Apresentamos tal síntese no quadro abaixo:

\begin{tabular}{|c|c|c|c|}
\hline $\begin{array}{l}\text { POSITIVISMO } \\
\text { HIPOTÉTICO } \\
\text { DEDUTIVO }\end{array}$ & $\begin{array}{l}\text { NEOPOSITIVISMO } \\
\text { (TEORÉTICO } \\
\text { QUANTITATIVO) }\end{array}$ & $\begin{array}{l}\text { MATERIALISMO } \\
\text { HISTÓRICO E } \\
\text { DIALÉTICO }\end{array}$ & $\begin{array}{c}\text { ABORDAGEM } \\
\text { FENOMENOLÓGICA }\end{array}$ \\
\hline August Comte & $\begin{array}{l}\text { Rigor matemático } \mathrm{e} \\
\text { Ciência de gabinete }\end{array}$ & De Marx e Engels. & $\begin{array}{l}\text { Corrente filosófica fundada } \\
\text { por Kant/Hegel/Husserl }\end{array}$ \\
\hline $\begin{array}{l}\text { Verdade absoluta, } \\
\text { Rigor matemático }\end{array}$ & $\begin{array}{l}\text { Quantitativíssimo } \mathrm{e} \\
\text { valorização da verdade } \\
\text { científica }\end{array}$ & $\begin{array}{l}\text { Negação da neutralidade, } \\
\text { uso da mediação, } \\
\text { posicionamento político do } \\
\text { pesquisador }\end{array}$ & $\begin{array}{l}\text { Busca ir além da essência dos } \\
\text { fenômenos }\end{array}$ \\
\hline $\begin{array}{lcc}\text { Foco } & \text { central } & \text { na } \\
\text { razão } & \mathrm{e} & \text { no } \\
\text { racionalismo } & \end{array}$ & $\begin{array}{l}\text { Uso da análise lógica } \\
\text { formal }\end{array}$ & $\begin{array}{llr}\text { Crítica ao } & & \text { sistema } \\
\text { econômico } & \text { e } & \text { as } \\
\text { desigualdades sociais } & \end{array}$ & Valorização dos sujeitos \\
\hline Indução & Neutralidade científica & $\begin{array}{l}\text { Ir além da aparência e das } \\
\text { formas }\end{array}$ & $\begin{array}{l}\text { Rompe com a oposição entre } \\
\text { sujeito e objeto }\end{array}$ \\
\hline Descrição & $\begin{array}{l}\text { Descrição, crítica à } \\
\text { generalidade e uso de } \\
\text { análises abstratas }\end{array}$ & $\begin{array}{l}\text { Busca entender as causas, a } \\
\text { estrutura, o processo, o } \\
\text { movimento }\end{array}$ & $\begin{array}{l}\text { Não vê problema no ecletismo } \\
\text { metodológico } \\
\text { epistemológico }\end{array}$ \\
\hline Enumeração & $\begin{array}{l}\text { Valorização do uso de } \\
\text { mapas, gráficos, } \\
\text { tabelas e quadros }\end{array}$ & $\begin{array}{lllr}\text { Observação } & & \text { das } \\
\text { contradições } & \text { e } & \text { uso } & \text { da } \\
\text { dedução } & & & \end{array}$ & $\begin{array}{l}\text { Valorização do espaço vivido, } \\
\text { do cotidiano }\end{array}$ \\
\hline $\begin{array}{l}\text { Observação } \\
\text { classificação }\end{array}$ & $\begin{array}{l}\text { Estudos pautados na } \\
\text { relação homem meio }\end{array}$ & $\begin{array}{l}\text { Valorização da relação } \\
\text { homem-natureza }\end{array}$ & $\begin{array}{l}\text { Uso das histórias orais, } \\
\text { poesias, músicas, literatura }\end{array}$ \\
\hline
\end{tabular}




\begin{tabular}{|c|c|c|c|}
\hline $\begin{array}{l}\text { Valorização } \\
\text { empirismo }\end{array}$ & $\begin{array}{l}\text { Saber a serviço do } \\
\text { estado e da classe } \\
\text { dominante }\end{array}$ & $\begin{array}{l}\text { Categorias: possibilidade, } \\
\text { realidade, matéria, } \\
\text { Consciência, qualidade, } \\
\text { Quantidade, causa e efeito. }\end{array}$ & $\begin{array}{l}\text { Leitura da subjetividade, } \\
\text { despir-se de elementos } \\
\text { teóricos a priori. }\end{array}$ \\
\hline $\begin{array}{l}\text { O objeto separasse } \\
\text { do sujeito }\end{array}$ & $\begin{array}{l}\text { O importante está na } \\
\text { produção de resultados }\end{array}$ & $\begin{array}{l}\text { Relação entre espaço } \\
\text { tempo }\end{array}$ & $\begin{array}{l}\text { Redução eidética: descrição } \\
\text { significativa, preocupação } \\
\text { não só com a essência mas } \\
\text { com a percepção do mundo }\end{array}$ \\
\hline O real é descrito & Não há & A análise marxista só faz & Uso da estética, do \\
\hline Por hipóteses & $\begin{array}{l}\text { Posicionamento } \\
\text { político do pesquisador }\end{array}$ & Sentido junto à prática & Imaginário e da percepção \\
\hline $\begin{array}{l}\text { A ideia permite a } \\
\text { elaboração de outra } \\
\text { ideia }\end{array}$ & Temas geométricos & 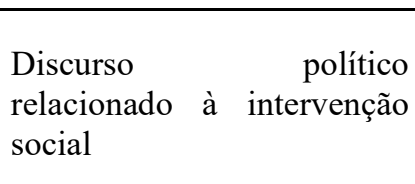 & $\begin{array}{l}\text { Intencionalidade (intentio): o } \\
\text { objeto nunca é o objeto em si, } \\
\text { é algo imaginado sobre ele }\end{array}$ \\
\hline $\begin{array}{l}\text { Neutralidade } \\
\text { científica }\end{array}$ & $\begin{array}{l}\text { Região como modelo } \\
\text { espacial }\end{array}$ & $\begin{array}{lr}\text { Espaço visto } & \text { como } \\
\text { reprodutor } & \text { das } \\
\text { desigualdades sociais } & \end{array}$ & $\begin{array}{l}\text { Suspensão (époche): deixar o } \\
\text { fenômeno falar por si só sem } \\
\text { produzir uma verdade } \\
\text { apressada }\end{array}$ \\
\hline
\end{tabular}

Fonte: BORGES (2013).

A pesquisa realizada foi descritiva, por se tratar de método de observação, registro, e análise e de interpretação objetiva dos fatos estudados. (LAKATOS, 2010). Ademais, adotouse a abordagem quantitativa e os procedimentos técnicos foram do tipo denominado de documental.

Foi utilizada para análise a Revista Hygeia, de periodicidade trimestral, por ser uma das principais revistas científicas a disseminar temas da Geografia da Saúde de forma interdisciplinar, tanto com as áreas da epidemiologia como da Saúde coletiva. (HYGEIA, 2019).

Logo, foi realizada a análise de todos os artigos publicados pela revista no ano de 2019, totalizando o número de 29 artigos acerca de GS, examinando-se qual (ou quais, uma vez que há pesquisas de metodologia eclética) corrente filosófica foi utilizada para o alcance de resultado em cada artigo, fazendo uso de tabela e gráfico para discussão. A partir dessa análise temporal, procuramos buscar as mais recentes pesquisas voltadas à área da GS. 


\section{RESULTADOS E DISCUSSÃO}

\subsection{As correntes filosóficas na Geografia da Saúde}

Os objetos e os métodos utilizados na corrente Positivista permitiram um número considerável de interações com o meio natural, influenciando fortemente os estudos relacionados à geografia médica e da saúde no Brasil em meados do século XIX e início do século XX. (DUTRA, 2011).

Com a interferência da corrente Neopositivista, a Geografia da Saúde procurou identificar regularidades nos modos de propagação de doenças no tempo e no espaço, ganhando enorme força na década de 1980, com os avanços da Informática e as novas ferramentas de software e de estatística, e para o mapeamento digital, Sistema de Informação Geográfica. (PEITER, 2005, p. 11).

Com o advento da Geografia Crítica, os conteúdos sociais tornam-se imprescindíveis para se compreender as questões ligadas à saúde. Com isso a nova Geografia da Saúde se associou com outros campos disciplinares, como são a Sociologia Médica, a Economia do Bemestar, a Administração Social e o Planejamento dos serviços de saúde, para o entendimento dos determinantes sociais da saúde (GUIMARÃES; PICKENHAYN; LIMA, 2014).

De forma geral, as abordagens e paradigmas que nortearam e norteiam a Geografia Médica/Saúde no Brasil ainda consistem no emprego de teorias deterministas ou possibilistas para o entendimento do processo saúde-doença, bem como dos paradigmas positivistas e neopositivistas; em menor escala encontram-se estudos de abordagem dialética envolvendo o materialismo histórico ou dialético com base na corrente Crítica. (GUIMARÃES; PICKENHAYN; LIMA, 2014).

Assim, como resultado, a corrente filosófica predominante encontrada nos artigos foi a positivista, com 66\% das publicações na revista Hygeia no ano de 2019 (o que corresponde a 19 artigos), coadunando com as afirmações de Guimarães, Pickenhayn e Lima (2014). As principais características desses artigos, seguiram a linha metodológica desta corrente, sobretudo, por apresentarem pesquisas quantitativas e descritivas, objetivando, por vezes, auxiliar o direcionamento das políticas de saúde pública, como pode ser observado no gráfico a seguir. 
Gráfico 1: Correntes filosóficas utilizadas nos artigos publicados na Hygeia no ano de 2019 (em \%).

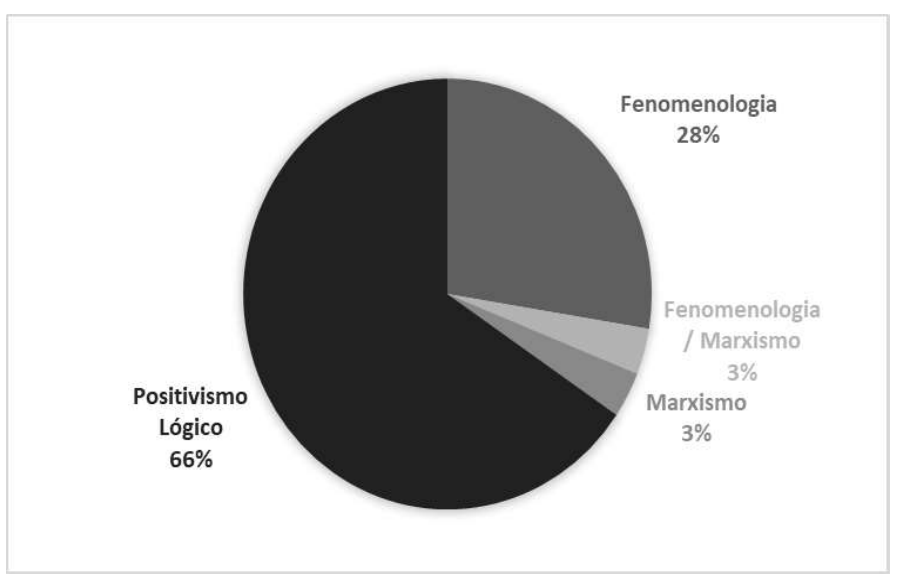

Fonte: elaborado pela autora.

Entre as vertentes da GS mais utilizada nessas publicações, a Geografia da Atenção Médica, presente em 20 dos 29 artigos analisados, se baseia na distribuição dos componentes dos sistemas de saúde a partir de modelos matemáticos e gráficos mais elaborados, ou seja, quantitativamente (PEITER, 2005). Posteriormente emergiu a vertente Nosogeográfica, que analisa as doenças em si e suas ocorrências. Essa estava presente em 9 dos 29 artigos analisados. Utiliza-se quase sempre a abordagem ecológica, que investiga tais enfermidades a partir do meio natural e físico. Tentando relacionar essas características com distribuição de doenças (PEITER, 2005), conforme é mostrado no quadro abaixo.

\subsubsection{Positivismo e Geografia da Saúde}

Como dito anteriormente, o Positivismo Lógico é uma corrente filosófica surgido no Círculo de Viena por volta do século XX. Para os defensores dessa corrente, para que um conhecimento seja considerado científico, faz-se necessário a aplicação do método indutivo. Toda e qualquer hipótese precisa passar por uma verificação e confirmação experimental. Uma teoria só é científica se puder ser empiricamente verificável. Além disso, o método neopositivista é baseado em leis matemáticas, como cálculos, gráficos e tabelas que permitirão uma análise quantitativa e não qualitativa sobre determinados problemas. Com base em tais características, foi possível identificar traços do Positivismo Lógico nos artigos listados no quadro abaixo. 
Quadro 02: Artigos da Geografia da Saúde enquadrados como positivismo lógico e demais características.

\begin{tabular}{|c|c|c|}
\hline TÍTULO & VERTENTE & ABORDAGEM \\
\hline $\begin{array}{l}\text { Estudo sobre a influência de variáveis meteorológicas nos casos de } \\
\text { acidentes por animais peçonhentos em Lages - SC }\end{array}$ & $\begin{array}{l}\text { Geografia da Atenção } \\
\text { Médica }\end{array}$ & Ecológica \\
\hline $\begin{array}{l}\text { A agricultura do agronegócio e sua relação com a intoxicação aguda por } \\
\text { agrotóxicos no Brasil }\end{array}$ & $\begin{array}{l}\text { Geografia da Atenção } \\
\text { Médica }\end{array}$ & Análise espacial \\
\hline Territorialização em saúde: conceitos, etapas e estratégias de identificação & $\begin{array}{l}\text { Geografia da Atenção } \\
\text { Médica }\end{array}$ & Análise espacial \\
\hline $\begin{array}{l}\text { Análise de sofrimento mental de trabalhadores que atuam no setor de } \\
\text { segurança privada }\end{array}$ & $\begin{array}{l}\text { Geografia da Atenção } \\
\text { Médica }\end{array}$ & Análise espacial \\
\hline $\begin{array}{l}\text { Transição demográfica, transição epidemiológica e envelhecimento } \\
\text { populacional no Brasil }\end{array}$ & $\begin{array}{l}\text { Geografia da Atenção } \\
\text { Médica }\end{array}$ & Análise espacial \\
\hline $\begin{array}{l}\text { Prevalência e fatores relacionados a transtornos mentais comuns entre } \\
\text { professores universitários de uma universidade federal brasileira }\end{array}$ & $\begin{array}{l}\text { Geografia da Atenção } \\
\text { Médica }\end{array}$ & Análise espacial \\
\hline $\begin{array}{l}\text { Monitoramento de Aedes Aegypti por ovitrampas e pelo método liraa em } \\
\text { salgueiro, Pernambuco, Brasil }\end{array}$ & $\begin{array}{l}\text { Geografia da Atenção } \\
\text { Médica }\end{array}$ & Análise espacial \\
\hline $\begin{array}{l}\text { Aspectos geográficos das consultas recebidas por tentativas de } \\
\text { autoeliminação na emergência do hospital Vilardebo na cidade de } \\
\text { Montevidéu, entre } 2014 \text { e } 2015\end{array}$ & $\begin{array}{l}\text { Geografia da Atenção } \\
\text { Médica }\end{array}$ & Análise espacial \\
\hline $\begin{array}{l}\text { Práticas alternativas, complementares e integrativas em saúde na cidade } \\
\text { de Campina Grande-PB: caracterização do setor privado de prestação de } \\
\text { serviços }\end{array}$ & $\begin{array}{l}\text { Geografia da Atenção } \\
\text { Médica }\end{array}$ & Análise espacial \\
\hline A regionalização da saúde: o caminho para o SUS em todos os territórios & $\begin{array}{l}\text { Geografia da Atenção } \\
\text { Médica }\end{array}$ & Análise Espacial \\
\hline O papel da geografia para a formação profissional para o SUS & $\begin{array}{l}\text { Geografia da Atenção } \\
\text { Médica }\end{array}$ & Análise espacial \\
\hline $\begin{array}{l}\text { Associação entre o índice de calor e internações por infarto agudo do } \\
\text { miocárdio em Manaus-AM }\end{array}$ & Nosogeográfica & Ecológica \\
\hline $\begin{array}{l}\text { Análise espacial e epidemiológica de hepatites } \mathrm{B} \text { e } \mathrm{C} \text { e índice de } \\
\text { desenvolvimento humano municipal, no estado do Pará }\end{array}$ & Nosogeográfica & Análise espacial \\
\hline $\begin{array}{l}\text { Distribuição espacial de criadouros de Aedes Aegypti em Jaguaruana-CE } \\
\text { - Brasil e suas correlações com indicadores sócio-demográficos }\end{array}$ & Nosogeográfica & Análise espacial \\
\hline $\begin{array}{l}\text { Contribuição do sistema ambiental urbano ao estudo da dengue em } \\
\text { Iranduba }\end{array}$ & Nosogeográfica & Ecológica \\
\hline $\begin{array}{l}\text { Incidência de doenças diarreicas na bacia do rio doce e possíveis relações } \\
\text { com infraestrutura de saneamento e o rompimento da barragem de fundão } \\
\text { - Mariana/MG. }\end{array}$ & Nosogeográfica & Ecológica \\
\hline $\begin{array}{l}\text { Padrões espaciais da ocorrência de leishmaniose visceral humana na } \\
\text { cidade de Natal-RN: a influência das áreas de risco social }\end{array}$ & Nosogeográfica & Ecológica \\
\hline $\begin{array}{l}\text { Análise exploratória dos dados climáticos e sua influência no Aedes } \\
\text { Aegypti, no município de Chapecó/SC: resultados parciais }\end{array}$ & Nosogeográfica & Ecológica \\
\hline $\begin{array}{l}\text { Análise espacial dos determinantes socioambientais para leptospirose no } \\
\text { município de Itaboraí-RJ, através da abordagem ecossistêmica }\end{array}$ & Nosogeográfica & Ecológica \\
\hline
\end{tabular}

Fonte: elaborado pela autora. 
Nesse sentido, o artigo "Associação entre o índice de calor e internações por infarto agudo do miocárdio em Manaus-AM" pode ser considerado positivista pois o pesquisador apresenta na sua metodologia características típicas do Positivismo Lógico, como o levantamento quantitativo, optando-se por métodos matemáticos para se encontrar o resultado almejado. Vejamos,

\begin{abstract}
Neste estudo, foram utilizados dados mensais de temperatura e umidade relativa do ar, no período de janeiro de 2000 a dezembro de 2017, coletados pela estação $\mathrm{N}^{\circ} 82331$ e disponibilizados pelo Banco de Dados Meteorológicos para Ensino e Pesquisa (BDMEP) pertencente ao Instituto Nacional de Meteorologia (INMET). Os dados epidemiológicos foram coletados junto ao banco de dados do Departamento de Informática do Sistema Único de Saúde (DATASUS) (MANDÚ et al, 2019, p. 18, grifo nosso).
\end{abstract}

Do mesmo modo, o artigo “Análise espacial e epidemiológica de Hepatites B e C e Índice de Desenvolvimento Humano municipal no estado do Pará, em que o autor aponta no resumo do artigo sua metodologia como:

\begin{abstract}
Foi realizado um estudo descritivo e transversal com dados o Ministério da Saúde e do Instituto Brasileiro de Geografia e Estatística. As análises epidemiológicas mostraram que o $1^{\circ} \mathrm{CRS}$ notificou maior número de casos, sobretudo em 2012 e 2014. O perfil dos indivíduos mais acometidos foi sexo masculino $(58,9 \%)$, pardos $(65,1 \%)$, adultos $(65,6 \%)$, baixa escolaridade $(27,3 \%)$ e residentes em zona urbana $(93,0 \%)$. (GONÇALVES et al, 2019, p.30, grifo nosso).
\end{abstract}

Em vista disso, pode-se depreender que tal metodologia é predominante principalmente para o levantamento de aspectos naturalísticos, como para o levantamento de casos de uma doença, áreas de maior incidência, etc., não sendo comum sua aplicabilidade para temáticas sociais.

No entanto, no artigo "Análise de sofrimento mental de trabalhadores que atuam no setor de segurança privada", ao fazer pesquisa sobre uma temática puramente social e até mesmo psicológica, o autor utiliza também da corrente típica das pesquisas de temáticas consideras "mais objetivas" como pode se observar,

Trata-se de uma pesquisa de estudo quantitativo, descritivo e bibliográfico. Elaborou-se no período de 2012 a 2015, para efeito de coleta e análise de dados, presente nos relatórios disponibilizados pelo Serviço Especializado em Engenharia de Segurança e Medicina do Trabalho (SESMT) da empresa. Não foi realizada nenhum tipo de abordagem aos trabalhadores e sim análises de relatórios disponibilizados pelo local do estudo. (FAGUNDES et al, 2019, p. 113-14, grifo nosso). 
Logo, vê-se que a corrente positivista pode ser aplicada às temáticas mais sociais e aparentemente subjetivas, ao pesquisador se distanciar dos aspectos subjetivos, estabelecendo o foco nos aspectos objetivos do caso, como no artigo dado como exemplo, no qual o autor fez análise objetiva de uma temática subjetiva como o "sofrimento mental", ao estabelecer como base para análise os relatórios disponibilizados pelo SESMT.

\subsubsection{Fenomenologia e Geografia da Saúde}

A Fenomenologia foi a segunda corrente mais adotada nos artigos da revista no ano de 2019, sendo encontrada em 9 artigos, o que corresponde a 31\% dos artigos analisados (vez que foi também encontrado um artigo de metodologia eclética com a corrente marxista). Tais trabalhos se caracterizam por buscar compreender os fenômenos além do que é aparente, pelo uso da percepção e pela não preocupação com resultados práticos.

Quadro 03: Artigos da Geografia da Saúde enquadrados como fenomenológico e demais características.

\begin{tabular}{|c|c|c|}
\hline TÍTULO & VERTENTE & ABORDAGEM \\
\hline $\begin{array}{l}\text { O olhar dos adolescentes sobre a violência e o lazer nos territórios pelas lentes } \\
\text { do photovoice. }\end{array}$ & $\begin{array}{l}\text { Geografia da Atenção } \\
\text { Médica }\end{array}$ & Análise espacial \\
\hline $\begin{array}{l}\text { Saberes tradicionais, biodiversidade, práticas integrativas e complementares: } \\
\text { o uso de plantas medicinais no SUS. }\end{array}$ & $\begin{array}{l}\text { Geografia da Atenção } \\
\text { Médica }\end{array}$ & Análise espacial \\
\hline $\begin{array}{l}\text { Regionalismo presente nos cardápios da alimentação escolar no município de } \\
\text { Campinorte - Goiás. }\end{array}$ & $\begin{array}{l}\text { Geografia da Atenção } \\
\text { Médica }\end{array}$ & Análise espacial \\
\hline Curandeiros parintintin e benzedeiras: reprodução do saber popular de cura. & $\begin{array}{l}\text { Geografia da Atenção } \\
\text { Médica }\end{array}$ & Análise espacial \\
\hline Concepções e experiências em cuidados paliativos no norte de Minas Gerais. & $\begin{array}{l}\text { Geografia da Atenção } \\
\text { Médica }\end{array}$ & Análise espacial \\
\hline $\begin{array}{l}\text { Práticas integrativas e complementares de saúde em Uberlândia, Minas } \\
\text { Gerais: o processo de implantação na perspectiva dos trabalhadores. }\end{array}$ & $\begin{array}{l}\text { Geografia da Atenção } \\
\text { Médica }\end{array}$ & Análise espacial \\
\hline $\begin{array}{l}\text { Políticas públicas na gestão de risco de desastres: um olhar para além da } \\
\text { resposta à emergência no sistema único de saúde. }\end{array}$ & $\begin{array}{l}\text { Geografia da Atenção } \\
\text { Médica }\end{array}$ & Análise espacial \\
\hline $\begin{array}{l}\text { Geografia do hiv/aids entre falas: análise do discurso de jovens soropositivos } \\
\text { em Presidente Prudente, SP. }\end{array}$ & Nosogeográfica & Análise espacial \\
\hline
\end{tabular}

Fonte: elaborado pela autora.

Por mais que o emprego desta corrente tenha se dado com inferioridade em relação ao Positivismo Lógico, seu uso ainda assim possui notoriedade, demonstrando que nas pesquisas de Geografia da Saúde há também viés de valorização do sujeito e sua percepção.

De fato, no artigo "O olhar dos adolescentes sobre a violência e o lazer nos territórios pelas lentes do Photovoice" demonstra a utilização da Abordagem Fenomenológica, pois revela a percepção dos adolescentes acerca da violência e o lazer no qual estão inseridos, ou seja, há 
foco na percepção dos sujeitos e uma leitura da subjetividade, características estas típicas da Fenomenologia, conforme palavras chaves grifadas na citação abaixo:

Esse cenário tem desafiado os agentes sociais institucionais que atuam na promoção dos direitos dos adolescentes: a compreensão do fenômeno ultrapassa a mera atuação sob os seus efeitos, como retirar os usuários dos locais de circulação da comunidade, em geral, e dos adolescentes, em particular. Uma vez que o fenômeno do consumo de drogas impacta nos comportamentos de todos os moradores de um determinado território. (SOUZA ARAGÃO et al, 2019, p. 7, grifo nosso).

Já no artigo "Geografia do HIV/Aids entre falas: análise do discurso de jovens soropositivos em Presidente Prudente, SP”, é possível perceber importante ligação com a corrente filosófica em questão, no seguinte trecho e palavras-chave grifadas,

Partir dos contextos geográficos dos jovens, teve-se como principal objetivo compreender os modos que os jovens vivenciam os processos de adoecimento a partir da análise dos discursos, e apontar quais são os impactos e ressignificações que ocorrem em suas práticas cotidianas. (PEDROSO e GUIMARÃES, 2019, p. 1, grifo nosso).

É importante enfatizar que, apesar de se tratar de temática que pode ser facilmente pesquisada a partir do método positivista, ou seja, a partir de levantamento de dados acerca do HIV entre jovens de Presidente Prudente, a pesquisa é feita a partir da percepção e experiência encontrada no discurso dos jovens que "vivenciam o adoecimento", análise notavelmente fenomenológica.

No artigo "Práticas integrativas e complementares de saúde em Uberlândia, Minas Gerais: o processo de implantação na perspectiva dos trabalhadores", é possível também denotar interessante percepção a partir do trecho, conforme palavras chaves grifadas na citação abaixo:

\footnotetext{
Trata-se de estudo qualitativo desenvolvido com entrevistas semiestruturadas com trabalhadores e gestores. As entrevistas foram analisadas de modo temático. [...] A entrevista semiestruturada permitiu ao entrevistado falar livremente sobre os temas propostos e, também, discorrer sobre aspectos não previstos preliminarmente. Essa técnica possibilitou rica abrangência do tema, valorizando as experiências dos participantes na descrição do processo de implantação das PICS em Uberlândia. (ALVES e QUERINO, 2019, p.1, grifo nosso).
}

Apesar do pesquisador se utilizar de uma entrevista previamente construída, o que poderia indicar entrevista objetiva levando a corrente positivista, há a preocupação com a percepção dos sujeitos e por isso se permite a liberdade de que falem livremente sobre os temas propostos, o que caracteriza tipicamente como fenomenológica. 


\subsubsection{Materialismo Histórico e Dialético e Geografia da Saúde}

A corrente do Materialismo Histórico e Dialético foi encontrada em 1 artigo e 1 outro artigo associado com a Fenomenologia.

Quadro 04: Artigos da Geografia da Saúde enquadrados como materialismo histórico e dialético e demais características.

\begin{tabular}{|l|l|l|}
\hline \multicolumn{1}{|c|}{ TíTULO } & \multicolumn{1}{c|}{ VERTENTE } & \multicolumn{1}{c|}{ ABORDAGEM } \\
\hline $\begin{array}{l}\text { Diálogos e interfaces da abordagem geográfica na educação profissional de } \\
\text { nível técnico em saúde }\end{array}$ & $\begin{array}{l}\text { Geografia da Atenção } \\
\text { Médica }\end{array}$ & Análise espacial \\
\hline Sofrimento patogênico de agentes comunitários de saúde em uma UBSF & $\begin{array}{l}\text { Geografia da Atenção } \\
\text { Médica }\end{array}$ & Análise espacial \\
\hline
\end{tabular}

Fonte: elaborado pela autora.

O artigo "Diálogos e interfaces da abordagem geográfica na educação profíssional de nível técnico em saúde", foi considerado como o único de metodologia puramente marxista. No texto, percebe-se com clareza a existência da corrente marxista posto que faz análise da relação de dominância, do espaço visto como reprodutor de desigualdades, utilizando-se da dialética para se discutir a temática, analisando o sujeito (o trabalhador) a partir de uma reconstrução e transformação, no caso em questão, a emancipação, como pode ser observado nas palavras do autor,

Possibilita desvendar as relações de produção e sociais concretas, de superar o existente, contidos nas contradições geradas pelo embate capital $\mathrm{x}$ trabalho, promovendo condições para a emancipação do trabalhador, seja em sua relação com o pensamento, seja em relação a ordem social e econômica imposta. (MONKEN, 2019, p.07, grifo nosso).

Como já mencionado, foi identificado entre o material pesquisado, artigo no qual se foi possível identificar duas correntes filosóficas norteadoras primeiramente, a Fenomenológica, vez que se optou por abordagem qualitativa conduzida pela observação dos participantes e não pelo rigor lógico matemático-positivista, ou seja, há total valorização da visão subjetiva do sujeito acerca do fenômeno estudado. E, por se tratar de corrente metodológica que aceita o ecletismo metodológico, em sua pesquisa é encontrada de forma secundária, a corrente marxista, posto que o pesquisador observa o agente comunitário de saúde à luz das desigualdades, dicotomias e contradições, fazendo-se crítica ao sistema de saúde pública vigente. 
Para tanto se propõe uma abordagem qualitativa, conduzida por meio da observação participante e entrevistas individuais semiestruturadas com agentes comunitários da Estratégia Saúde da Família do Município de Uberlândia MG. [...] Quanto ao papel de mobilização o ACS fica em situação em que não tem como propor nada junto a população, uma vez que pouco tem a oferecer: as consultas especializadas e exames entram em fila de espera, medicação em falta, dentre outras situações em que fogem de suas alçadas. Se fizerem mobilização seria como um levante contra o próprio sistema buscando melhorias, o que entra em contradição com sua própria condição de trabalhador. Assim, entre essas nuances o ACS vive a dicotomia de estar a serviço de uma população, cujos recursos são escassos e sem condições de oferecer algo que realmente faça a mudança na vida destas pessoas. Dessa forma, é questionável se o ACS poderia estar livre dos conflitos que fazem parte de sua vivência pessoal e no trabalho. (ALVES e QUIRINO, 2019, p. 01, grifo nosso).

Esta pesquisa investigou quais métodos mais utilizados para a pesquisa em Geografia da saúde e como cada corrente filosófico-metodológica pode contribuir para a o estudo da área. Para isso, realizou-se inicialmente, um levantamento bibliográfico sobre a compreensão das correntes filosóficas. A fonte de análise utilizada foi a Revista Hygeia, de periodicidade trimestral, por ser a principal revista científica a publicar acerca dos temas da Geografia médica e da saúde, em interdisciplinaridade, tanto com as áreas da epidemiologia como da Saúde coletiva.

O Estudo aconteceu com a análise de todos os artigos publicados pela revista no ano de 2019, totalizando o número de 29 artigos acerca de Geografia da Saúde, examinando-se qual (ou quais, uma vez que há pesquisas de metodologia eclética) corrente filosófica foi utilizada para o alcance de resultado em cada artigo, fazendo uso de tabela e gráfico para discussão.

Essa pesquisa insere-se dentro da corrente positivista pois é descritiva, por se tratar de método de observação, registro, e análise de interpretação objetiva dos fatos estudados de maneira quantitativa, cujos procedimentos técnicos adotados foram do tipo denominado de documental conforme a corrente do positivismo lógico.

Compreende-se que no Positivismo e no Neopositivismo há a valorização do objeto e do concreto. Já com relação ao Materialismo Histórico e Dialético o sujeito se transforma se reconstrói. Enquanto na Abordagem Fenomenológica há valorização dos sujeitos. Portanto fazse necessário uma avaliação crítica de cada método.

\section{CONSIDERAÇÕES FINAIS}

Assim, a corrente filosófica predominante encontrada nos artigos foi a positivista, com $66 \%$ dos artigos publicados na revista no ano de 2019 (o que corresponde a 19 artigos). Esse 
resultado foi interpretado, através da análise das principais características desses artigos, seguiram a linha metodológica desta corrente, sobretudo, por apresentarem pesquisas quantitativas e descritivas, objetivando, por vezes, auxiliar o direcionamento das políticas de saúde pública. Os principais temas tratados em cada corrente estavam relacionados as vertentes da geografia da saúde. A que se destacou foi a vertente atenção médica que estava presente em 20 dos 29 artigos analisados.

Em seguida aparece a vertente nosogeográfica, que analisa as doenças em si e suas ocorrências. Essa estava presente em 9 dos 29 artigos analisados. Utiliza-se quase sempre a abordagem ecológica, que investiga tais enfermidades a partir do meio natural e físico. É importante destacar que a Fenomenologia foi a segunda corrente mais adotada nos artigos da revista no ano de 2019, sendo encontrada em 9 artigos, o que corresponde a $31 \%$ dos artigos analisados. Por mais que o emprego desta corrente tenha se dado com inferioridade em relação ao Positivismo Lógico, Seu uso ainda assim possui notoriedade, demonstrando que nas pesquisas de Geografia da Saúde há também viés de valorização do sujeito e sua percepção. Por fim, A corrente do Materialismo Histórico e Dialético foi encontrada de maneira explicita em apenas 1 artigo, sendo que um outro fazia forte associação com a Fenomenologia.

Há ainda necessidade em se realizar outros tipos de pesquisas sobre o assunto, utilizando um maior intervalo de tempo como, por exemplo, estudo de levantamento bibliométricos que seria um excelente indicador de tendências, crescimentos das correntes filosóficas na área de Geografia da saúde.

Esta pesquisa, assim, oferece uma contribuição teórica para ampliação do conhecimento relacionado as correntes filosóficas e Geografia da Saúde. Constata-se, apesar das variedades das discussões, nesse período analisado, há um forte domínio da visão metodológica do positivismo no âmbito dos estudos da Geografia da saúde, visando, muitas vezes, na contribuição de políticas de saúde pública.

\section{REFERÊNCIAS}

ALVES, C. M.; QUERINO, R. A. Práticas integrativas e complementares de saúde em uberlândia, minas gerais: o processo de implantação na perspectiva dos trabalhadores. Hygeia - Revista Brasileira de Geografia Médica e da Saúde, v. 15, n. 32, p. 149-163, 23 out. 2019. Disponível em: https://doi.org/10.14393/Hygeia153246912. Acesso em: 10 de fev.2020.

BORGES, J. DE A. Os enfoques e os olhares do geógrafo: uma abordagem metodológica sobre método, metodologia e técnicas de pesquisa. Observatorium: Revista Eletrônica de 
Geografia, v. $7, \quad$ n. 19,13 nov. 2018. Disponível em: http://www.seer.ufu.br/index.php/Observatorium/article/view/45851/24535. Acesso em: 15 de fev.2020.

DUTRA, Denicir de Almeida. Geografia da saúde no Brasil: Arcabouço Teórico Epistemológico, temáticos e desafios UFPR. 2011. 191 f. Tese (Doutorado em geografia) Curso de Pós-Graduação em Geografia, Setor de Ciências da Terra, da Universidade Federal do Paraná, Curitiba (PR).

FAGUNDES, A. C.; AQUINO, R. L. DE; MENDES, P. C. análise de sofrimento mental de trabalhadores que atuam no setor de segurança privada. Hygeia - Revista Brasileira de Geografia Médica e da Saúde, v. 15, n. 32, p. 54-68, 23 out. 2019 Disponível em: https://doi.org/10.14393/Hygeia153247545. Acesso em:10 de fev.2020.

GUIMARÃES, Raul Borges; PICKENHAYN, Jorge Amancio; LIMA, Samuel do Carmo. Geografia e saúde sem fronteiras. Uberlândia: Assis, 2014.

GONÇALVES, N. V.; VIEIRA, D. C.; MIRANDA, C. DO S. C.; PALÁCIOS, V. R. DA C. M.; COSTA, S. B. N. DA; GUEDES, J. A.; SANTOS, B. DE O.; COSTA, R. J. F. DA; E SILVA, S. C. M.; OLIVEIRA, R. A. C. DE. Análise espacial e epidemiológica de hepatites b e c e índice de desenvolvimento humano municipal, no estado do Pará. Hygeia - Revista Brasileira de Geografia Médica e da Saúde, v. 15, n. 31, p. 29 - 42, 5 jul. 2019. Disponível em: https://doi.org/10.14393/Hygeia153146170. Acesso em:10 de Fev. 2020.

IÑIGUEZ ROJAS, L. Geografía y salud: temas y perspectivas en América Latina. Brasil: Cadernos de Saúde Pública - Escola Nacional de Saúde Pública, Fundação Oswaldo Cruz, 2004. Disponível em: http://site.ebrary.com/lib/ifac/docDetail.action?docID=10068656 \&gt. Acesso em:27 Fev. 2020.

LACAZ, Carlos da Silva. Conceituação, atualidade e interesse do tema. Súmula histórica. In: LACAZ, Carlos da Silva. BARUZZI, Roberto G. SIQUEIRA JR, Waldomiro. Introdução à geografia médica do Brasil. São Paulo: Edgard Blücher, 1972. Pag. 01 - 22.

LAKATOS, Eva Maria. Fundamentos de metodologia científica. 7.ed.- São Paulo: atlas 2010. MANDÚ, T. B.; DOS SANTOS GOMES, A. C.; DO VALE, R. S.; DOS SANTOS, M. S. Associação entre o índice de calor e internações por infarto agudo do miocárdio em manausam. Hygeia - Revista Brasileira de Geografia Médica e da Saúde, v. 15, n. 31, p. 16 - 28, 3 jul. 2019. Disponível em: http://www.seer.ufu.br/index.php/hygeia/article/view/44189. Acesso em: 10 de Fev. 2020.

MONKEN, M. diálogos e interfaces da abordagem geográfica na educação profissional de nível técnico em saúde. Hygeia - Revista Brasileira de Geografia Médica e da Saúde, v. 15, n. 33, p. 83-90, 22 nov. 2019. Disponível em: https://doi.org/10.14393/Hygeia153351679. Acesso em: 10 de Fev.2020.

PEDROSO, M. F.; GUIMARÃES, R. B. geografia do hiv/aids entre falas: análise do discurso de jovens soropositivos em Presidente Prudente, SP. Hygeia - Revista Brasileira de Geografia Médica e da Saúde, v. 15, n. 31, p. 82 - 94, 9 jul. 2019. Disponível em: https://doi.org/10.14393/Hygeia153146917. Acesso em:10 Fev.2020 
PEITER, Paulo. A Geografia da Saúde na Faixa de Fronteira Continental do Brasil na Passagem do Milênio. Tese de doutorado. PPGG/UFRJ, julho de 2005.

SANTOS, J. E. dos. Introdução à geografia: correntes filosóficas que influenciaram e influenciam o ensino e a pesquisa em geografia. GEOTEMAS: Revista Eletrônica, v.5. n1, p. 63-79, Jun (2015).

Disponível em: http://periodicos.uern.br/index.php/geotemas/article/view/1376. Acesso em:15 de Fev. de 2020.

SOUZA ARAGÃO, A.; ALVES QUERINO, R.; SILVEIRA GOMES, L. C.; TRAJANO DA SILVA, L.; BIZINOTO CAETANO, M. C.; LOYOLA MARTINS, O.; AMATÂNGELO OLIVEIRA, A. A.; GRANER ARAÚJO OLIVEIRA, A. C.; LOPES SANTOS, M.; OLIVEIRA SABINO, F. H. O olhar dos adolescentes sobre a violência e o lazer nos territórios pelas lentes do photovoice. Hygeia - Revista Brasileira de Geografia Médica e da Saúde, v. 15, n. 31, p. 1 - 15, 3 jul. 2019. Disponível em: https://doi.org/10.14393/Hygeia153143020. Acesso em: 10 Fev. de 2020.

SPOSITO, Eliseu Savério. Geografia e Filosofia - Contribuição para o ensino do pensamento geográfico. São Paulo: UNESP, 2004.

TRIVIÑOS, Augusto Nibaldo Silva. O problema de pesquisa. In: TRIVIÑOS, Augusto Nibaldo Silva. Introdução à pesquisa em Ciências Sociais: a pesquisa qualitativa em educação. São Paulo: Atlas, 1987. p. $30-90$. 